\title{
In memoriam du Dr Antoine Denis
}

\section{In memoriam: Doctor Antoine Denis}

\section{Huber-Levernieux}

(C) Springer-Verlag France 2011

Le Dr Antoine Denis nous a quittés le 14 décembre 2010, dans sa $90^{\mathrm{e}}$ année.

Il s'était intéressé dès le début de sa carrière à la rhumatologie naissante, mais son expérience de la chirurgie acquise au cours de la Seconde Guerre mondiale auprès du Pr Jean Debeyre a été le point de départ de son intérêt pour la chirurgie du pied. Son originalité a été de toujours savoir garder un œil et un raisonnement médical et rhumatologique, ce qui faisait de lui un clinicien et un chirurgien averti et sélectif dans ses indications opératoires. De nombreuses publications, un précis concis, pratique et très didactique de pathologie du pied, ont fait apprécier son esprit curieux et ses qualités d'enseignant, son expérience des affections inflammatoires aussi bien que mécaniques ou dégénératives. Tout au long de sa carrière, il est resté fidèle à ses maitres, Stanislas De Sèze à l'hôpital Lariboisière et Jean Debeyre à Henri-Mondor et à leurs successeurs, en particulier Daniel Goutallier.

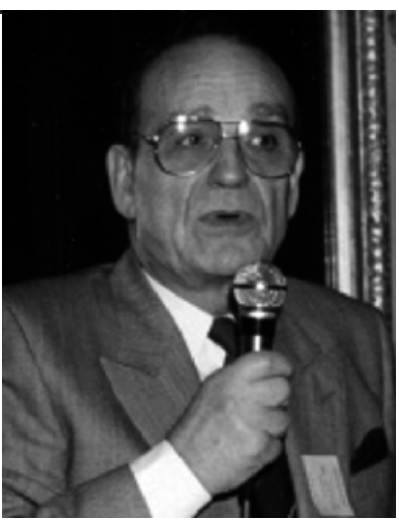

Il a été président de la Société française de médecine et de chirurgie du pied de1989 à 1991, mais cet épisode de sa vie ne l'a pas détourné de bien d'autres centres d'intérêt : tout d'abord le dessin, avec un don marqué pour les caricatures, la pratique de l'aquarelle puis de la peinture ont longtemps occupé ses loisirs, remplacés ensuite par sa passion pour l'histoire. Il a brillamment obtenu un doctorat d'histoire à la Sorbonne avec les félicitations du jury et a écrit plusieurs ouvrages remarquables dans sa nouvelle résidence d'Albi où il était aussi expert en matière de jardinage et de fleurs.

Mais cet « honnête homme » à la culture immense et aux qualités multiples n'a pas été épargné par les épreuves à la fin de sa vie, dont la plus rude a été la disparition de son fils ainé Marc.

Il a maintenant trouvé la paix. Nous partageons tous la peine de Claire, Chantal, Jean-Christophe, de l'épouse de Marc et de toute sa famille. 